\section{Arkivoc

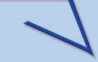

Archive for

Organic Chemistry
The Free Internet Journal

for Organic Chemistry
Review

Arkivoc 2017, part ii, 324-344

\title{
P-C bond formation in reactions of Morita-Baylis-Hillman adducts with phosphorus nucleophiles
}

\author{
Michał Talma and Artur Mucha* \\ Department of Bioorganic Chemistry, Wrocław University of Technology, Wybrzeże Wyspiańskiego 27, \\ 50-370 Wrocław, Poland \\ Email: artur.mucha@pwr.edu.pl
}

Dedicated to Prof. Jacek Młochowski on the occasion of his $80^{\text {th }}$ anniversary

Received 07-07-2016

Accepted 09-09-2016

Published on line 10-11-2016

\begin{abstract}
Morita-Baylis-Hillman adducts (e.g., activated allyl acetates or bromides) are an unprecedented trifunctional synthetic platform for diverse types of nucleophilic displacements, additions and rearrangements. These reactions can proceed in an inter- or intramolecular manner, and with stereoselective induction. Accordingly, they contribute, as the key steps, to numerous synthetic pathways, including the total syntheses of natural products of various classes and to novel strategies leading to medicinally relevant compounds and commercialized drugs. The synthetic feasibility of the Morita-Baylis-Hillman adducts in organophosphorus chemistry has been explored to a relatively low extent. In this review, we summarize the current state of the art on the formation of the C-P bond by means of the title reactions. The scope of the processes, the stereochemistry of the products and their further synthetic relevance to obtain multifunctional compounds, including those that are biologically active, are summarized.
\end{abstract}

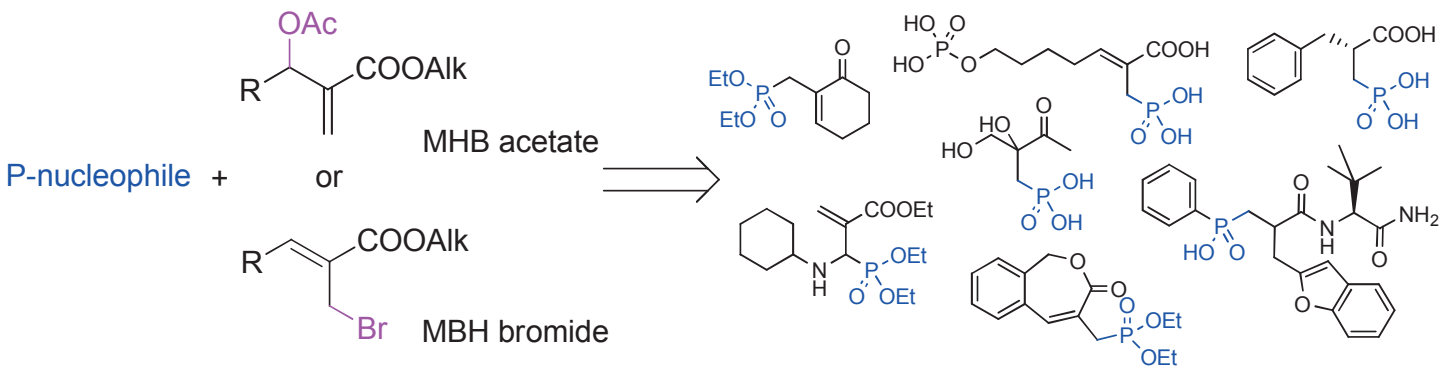

Keywords: Nucleophilic substitution, allyl acetates and bromides, organophosphorus chemistry, multifunctional compounds 


\section{Table of Contents}

1. Introduction

2. Reactivity of the Morita-Baylis-Hillman Acetates with Phosphorus Nucleophiles

3. Reactivity of the Morita-Baylis-Hillman Bromides with Phosphorus Nucleophiles

4. Structural Diversification, Application and Future Potential of Allylphosphonates

5. Conclusions

\section{Introduction}

The Morita-Baylis-Hillman ( $\mathrm{MBH}$ ) reaction has recently emerged as one of the most creative and intellectually inspiring carbon-carbon bond formation reactions. ${ }^{1-5}$ It involves the condensation of a carbon electrophile with the $\alpha$ position of an activated unsaturated compound (Scheme 1). Aldehydes, ketones and suitably protected imines (aza-MBH reaction) ${ }^{6}$ are typical electrophilic components, while alkenes, alkynes and allenes substituted with a carbonyl-, carboxyl-, phosphonate-, or sulfonate-type functionality result in a diversity of unsaturated compounds. The reaction is catalyzed by tertiary amines, typically DABCO (rarely, stronger bases) or phosphines, and proceeds in an elegant, atom-economic and operationally simple manner.

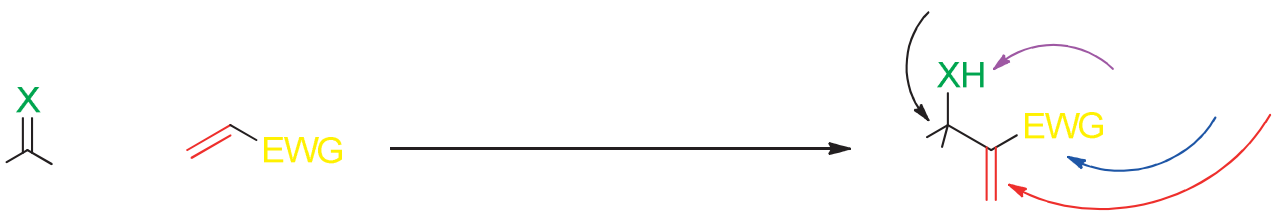

$X=\mathrm{O}, \mathrm{N}-\mathrm{COOR}, \mathrm{N}-\mathrm{Ts}, \mathrm{N}-\mathrm{P}(\mathrm{O}) \mathrm{R}_{2}$, etc

Scheme 1. General features of the Morita-Baylis-Hillman reaction. For simplicity, the unsaturated component is presented as the fundamental, non-substituted version.

The major potential of the Morita-Baylis-Hillman reaction is in its opportunity to provide practically unlimited structural combinations of readily available substrates. In addition, owing to the nascent chiral center, enantiomerically enriched compounds can be obtained from prochiral electrophiles. ${ }^{7}$ The stereoselectivity can be induced by chiral substrates, catalysts or the reaction environment. The ultimate benefit is the synthetic feasibility of the products, the Morita-Baylis-Hillman adducts. ${ }^{8}$

The predominating preparative utility of the $\mathrm{MBH}$ adducts originates from the susceptibility of the allylic / $\alpha, \beta$-unsaturated system to nucleophilic substitution and addition. ${ }^{3-8}$ The mechanism and the position of the displacements strongly depend on the structure of the substrates and the manipulation conditions (Scheme 2). Attack on the primary $\mathrm{MBH}$ adducts, allyl alcohols, typically proceeds according to a mechanism of Michaeltype addition of a nucleophile to the electrophilic terminal carbon of an activated unsaturated system (Scheme 2A). When a hydroxyl is converted into a good leaving group, such as an acetoxy, the electrophilic character of the allylic position is also pronounced. Under organocatalytic conditions in organic solvents, a range of nucleophiles reacts in a sequential addition-elimination process referred to as $S_{N} 2$ '. This leads to the substitution of the olefinic position and the double bond rearrangement (Scheme 2B). However, under certain 
conditions (a Lewis base, aqueous media), the addition of the catalytic base and the leaving group elimination result in the formation of an intermediate that undergoes subsequent attack. The overall effect of the $\mathrm{S}_{\mathrm{N}} 2$ '$\mathrm{S}_{\mathrm{N}} 2$ ' process is substitution at the position of the leaving acetoxy group (Scheme $2 \mathrm{C}$ ). The same regio-directing effect can be achieved by palladium-catalyzed reactions, e.g., allylic alkylation (the Tsuji-Trost reaction). ${ }^{9}$ Thus, two products of different constitutions can be obtained, depending on whether the attacking nucleophile substitutes at the primary or secondary position (the $\alpha$ or $\gamma$ position of the allylic system). Complete regioselectivity, easily available for the acetoxy and related oxygen-based leaving groups, is not evident in the case of 2-bromomethylalk-2-enoates (MBH bromides, see below for further discussion of their reactivity with phosphorus nucleophiles).
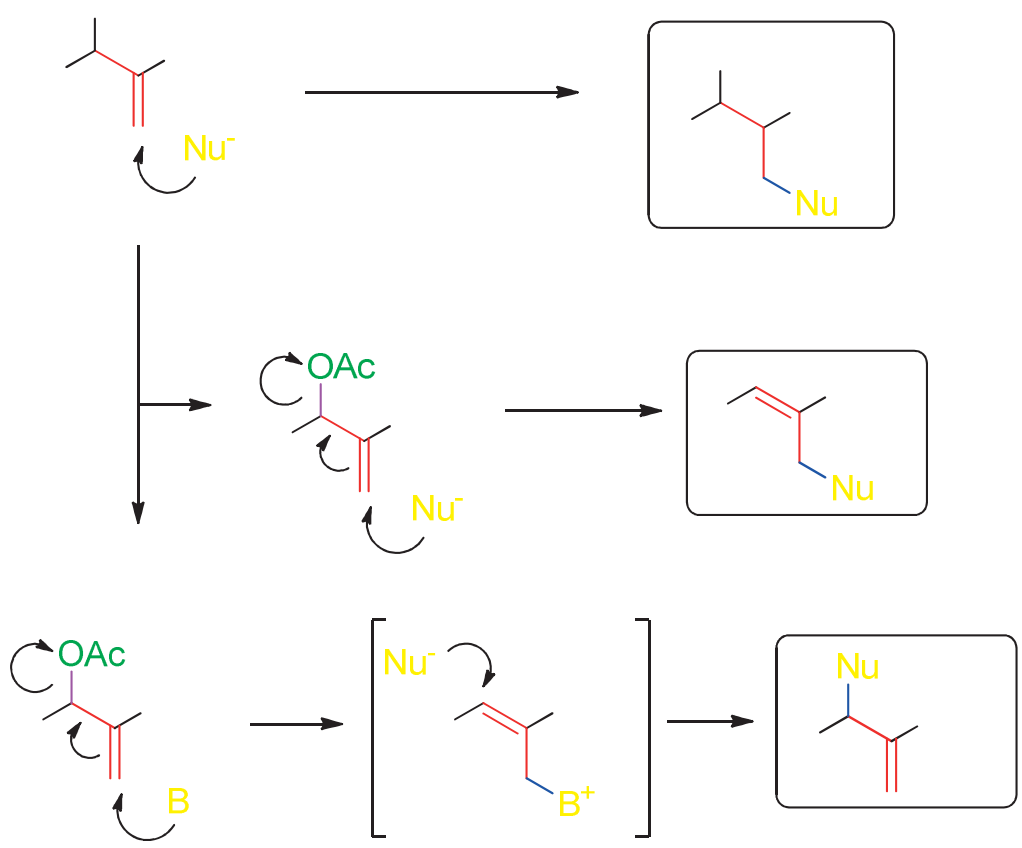

Scheme 2. Mechanistic aspects and regioselectivity of the nucleophilic substitution in the Morita-BaylisHillman alcohols and acetates.

The diversity of carbon, oxygen, nitrogen and halogen nucleophiles contributed to applications of the Morita-Baylis-Hillman reaction in innovative synthetic developments, including advanced asymmetric transformations and cyclic framework preparations. ${ }^{3-8}$ The potential of the reactivity of MBH adducts towards phosphorus nucleophiles seems not to have been extensively explored as yet and hardly extends beyond a few types of simple P-compounds and $\mathrm{MBH}$ adducts. Dialkyl and trialkyl phosphites, which substitute for the electrophilic components according to the Arbuzov reaction mechanism following the general rules outlined in Scheme 2, have been the most documented. Recently, this situation has been dynamically changing, as several new developments and achievements have been published. To follow the interests in this review, we present a summary of the knowledge, given in both a fundamental and perspective context.

\section{Reactivity of the Morita-Baylis-Hillman Acetates with Phosphorus Nucleophiles}

The substitution of allyl acetates with dialkyl (in general, the Michaelis-Becker reaction) and trialkyl phosphites 
(Michaelis-Arbuzov reaction) can be considered as the prototypical example of the reactivity of phosphorus nucleophiles with $\mathrm{MBH}$ adducts. In the fundamental work of Basavaiah and Pandiaraju, the authors heated an excess of $\mathrm{P}(\mathrm{OEt})_{3}$ with $\alpha, \beta$-unsaturated acetoxyesters and nitriles, prepared from aliphatic and aromatic aldehydes. ${ }^{10}$ They obtained corresponding primary allylphosphonates with an excellent yield and significant diastereoselectivity. Interestingly, the $Z$ isomer predominated (up to $>90: 10$ ) for the esters (Table 1, Entry 1), while the $E$ isomer predominated for nitriles.

Dialkyl phosphites (H-phosphonates) are phosphorus esters that are much less nucleophilic than their tervalent counterparts. To be satisfactorily reactive, they are usually applied in the presence of a base. Alternatively, to follow the Arbuzov mechanism, they can be treated with a silylating agent. This is demanded to shift the tautomeric equilibrium from the $\mathrm{HP}(\mathrm{O})(\mathrm{OAlk})_{2}$ form to either the ${ }^{-} \mathrm{OP}(\mathrm{OAlk})_{2}$ or $\mathrm{Alk}{ }_{3} \mathrm{SiOP}(\mathrm{OAlk})_{2}$ species. In both versions, the choice of the reagents and reaction conditions is quite broad. To mention representative examples, Kraïem and Amri substituted alkyl-substituted MBH acetates with diethyl phosphite using anhydrous potassium carbonate and a quaternary dibutylammonium salt, heating the solventless reaction mixture to $70{ }^{\circ} \mathrm{C}^{11}$ The yield of the reaction was good, and the diastereomeric ratio of the products was shifted towards the $Z$ form (Table 1, Entry 2). Spilling et al. activated diverse dialkyl phosphites with bis(trimethylsilyl)acetamide (BSA) and treated such mixed dialkyl trimethylsilyl triesters with $\mathrm{MBH}$ acetates. ${ }^{12}$ The yields of the substitution were also good, with the exception of dibenzyl phosphite (Table 1, Entry 3 ). For a range of aromatic substrates and ester groups larger than methyl, $Z$ stereochemistry was exclusively evidenced.

Table 1. Reactions of dialkyl and trialkyl phosphites with the Morita-Baylis-Hillman acetates

\begin{tabular}{|c|c|c|c|c|c|}
\hline Entry & Alk, $R$ & Conditions & Yield (\%) & $Z: E(\%)$ & Ref. \\
\hline 1 & $\begin{array}{c}\text { Alk = Et } \\
\mathrm{R}=\text { alkyl, } \operatorname{aryl}(6 \text { examples) }\end{array}$ & $\mathrm{P}(\mathrm{OEt})_{3}, 80^{\circ} \mathrm{C}$ & $87-95$ & $68: 32-93: 7$ & 10 \\
\hline 2 & $\begin{array}{c}\text { Alk = Et } \\
\mathrm{R}=\text { alkyl (4 examples) }\end{array}$ & $\begin{array}{c}\mathrm{HP}(\mathrm{O})(\mathrm{OEt})_{2}, \mathrm{~K}_{2} \mathrm{CO}_{3}, \\
\text { TBAHS (3 mol\%), } 70^{\circ} \mathrm{C}\end{array}$ & $70-86$ & $63: 37-87: 13$ & 11 \\
\hline 3 & $\begin{array}{c}\text { Alk }=\text { Me, } t \text {-Bu } \\
R=\text { Me, aryl, 2-furyl } \\
\text { (11 examples) }\end{array}$ & $\begin{array}{c}\mathrm{HP}(\mathrm{O})\left(\mathrm{OR}^{\prime}\right)_{2}, \mathrm{BSA} \\
\mathrm{R}^{\prime}=\text { alkyl, } \mathrm{Bn}\end{array}$ & $27-85$ & $83: 17-100: 0$ & 12 \\
\hline
\end{tabular}

An acetoxy group and an alkyl phosphite can be considered as a typical pair for the leaving moiety in reactive $\mathrm{MBH}$ adducts and the attacking P-nucleophile, by which the substitution proceeds according to the $\mathrm{S}_{\mathrm{N}} 2$ ' mechanism and primary phosphonate products are obtained. Nevertheless, other functionalities (in general, oxygen-containing) behave according to the same scenario. For example, Janecki and Bodalski performed an interesting intramolecular version of the substitution (phosphorus-leaving and attacking group). ${ }^{13}$ First, the $\mathrm{MBH}$ alcohols were phosphitylated with diethyl chlorophosphite to afford the corresponding mixed trialkyl phosphites. These intermediates, without preparative separation, were converted into the phosphonates upon heating (Scheme 3). The yields were reasonable (61-68\%, 5 examples), 
and significantly, the stereochemistry was assigned as exclusively $Z$. For nitriles, the form $E$ again predominated. ${ }^{13}$ The method of Janecki and Bodalski has been broadly followed as a synthetic shortcut to primary phosphonates that omits the step of preparation of the $\mathrm{MBH}$ acetates.
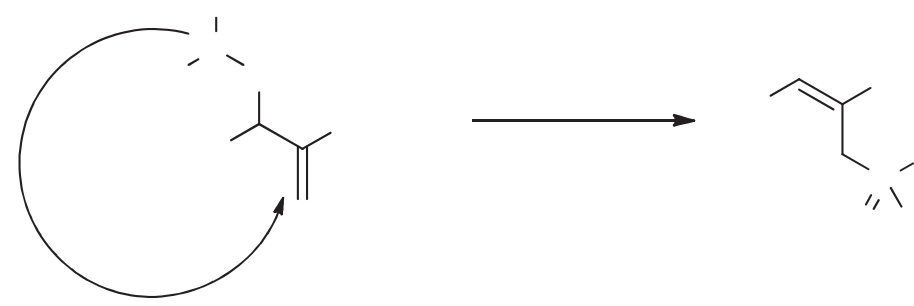

Scheme 3. Rearrangement of MBH phosphites to primary allylphosphonates.

Phosphate esters were also considered as good leaving groups in the substitution of cyclic allyl systems with trimethyl phosphite performed by Krawczyk et al. ${ }^{14}$ The phosphonylation demonstrated striking regioand stereoselectivity. Single diastereoisomers were obtained from MBH phosphates, derivatives of chiral methyl- or phenyl-substituted six-membered rings (Scheme 4). The P-nucleophile attacked exclusively at the position anti to the leaving group. Significantly, reactions with other nucleophiles, e.g., amines, was not so rigorously discriminated.

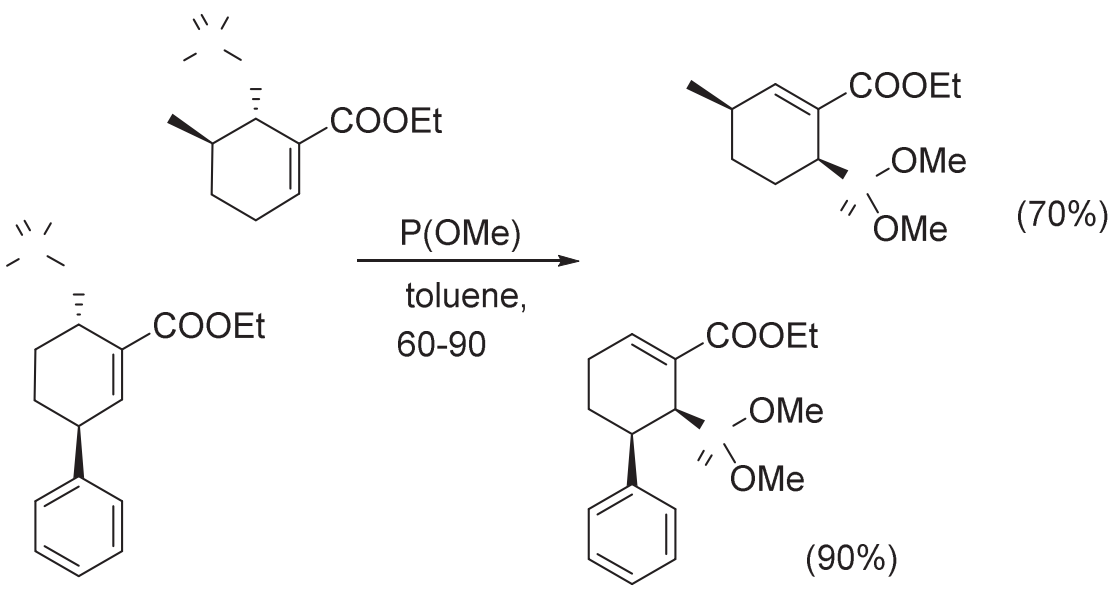

Scheme 4. Regio- and stereoselective substitution of cyclic MBH phosphates with trimethyl phosphite.

To reveal the reasons for the unexpected stereoselectivity of the reaction of the MBH acetates with phosphorus ester, Kalvya et al. recently presented a comprehensive study on the mechanistic aspects of the substitution with bistrimethylsilyl phenyl phosphonite as a model substrate. ${ }^{15}$ Indeed, the prevailing occurrence of the $Z$ product for esters and $E$ for nitriles was also confirmed. It was shown experimentally that the initial Michael-type addition, preceding the elimination, was not a rate-determining step of a presumed addition-elimination process. Plausible intermediate ketene silyl enolates could not be trapped by an IrelandClaisen rearrangement performed for the substrate of a particular structure designed for this purpose (Scheme 5). 


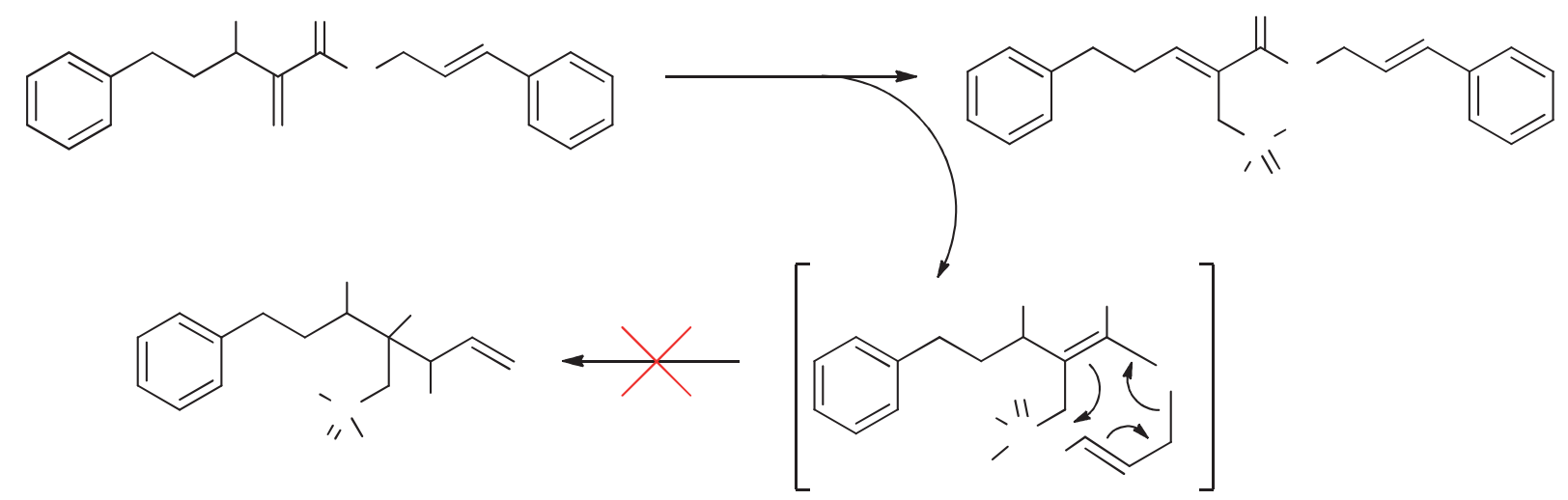

Scheme 5. The excluded mechanism of the initial Michael-type addition in a presumed addition-elimination process of the $\mathrm{MBH}$ acetate substitution with bis(trimethylsilyl) phenylphosphinate.

Instead, structural parameters obtained from DFT calculations revealed the difference in the transition states of the classical mechanism: "early" substrate-like for nitriles and "late" product-like for esters. The lastmentioned advanced state was postulated to discriminate bulky substituents, e.g., aromatic in proximity to the ester group because of the evident unfavorable steric constraint. This was supported by the Gibbs free energy differences calculated for the cis and trans conformers of the substrates and intermediates.

The reactivity of the silylated phosphinic acids, in particular derivatives of $\alpha$-aminoalkyl- $H$-phosphinic acids, has an important applicative context. The addition of these compounds prepared in situ to MBH acetates was proposed as a method to obtain phosphinic dipeptide analogues in an approach that was an alternative to the typically applied phospha-Michael addition or three-component amidoalkylation. ${ }^{15,16}$ The method is of particular importance for "difficult" sequences, poorly available classically (Scheme 6).
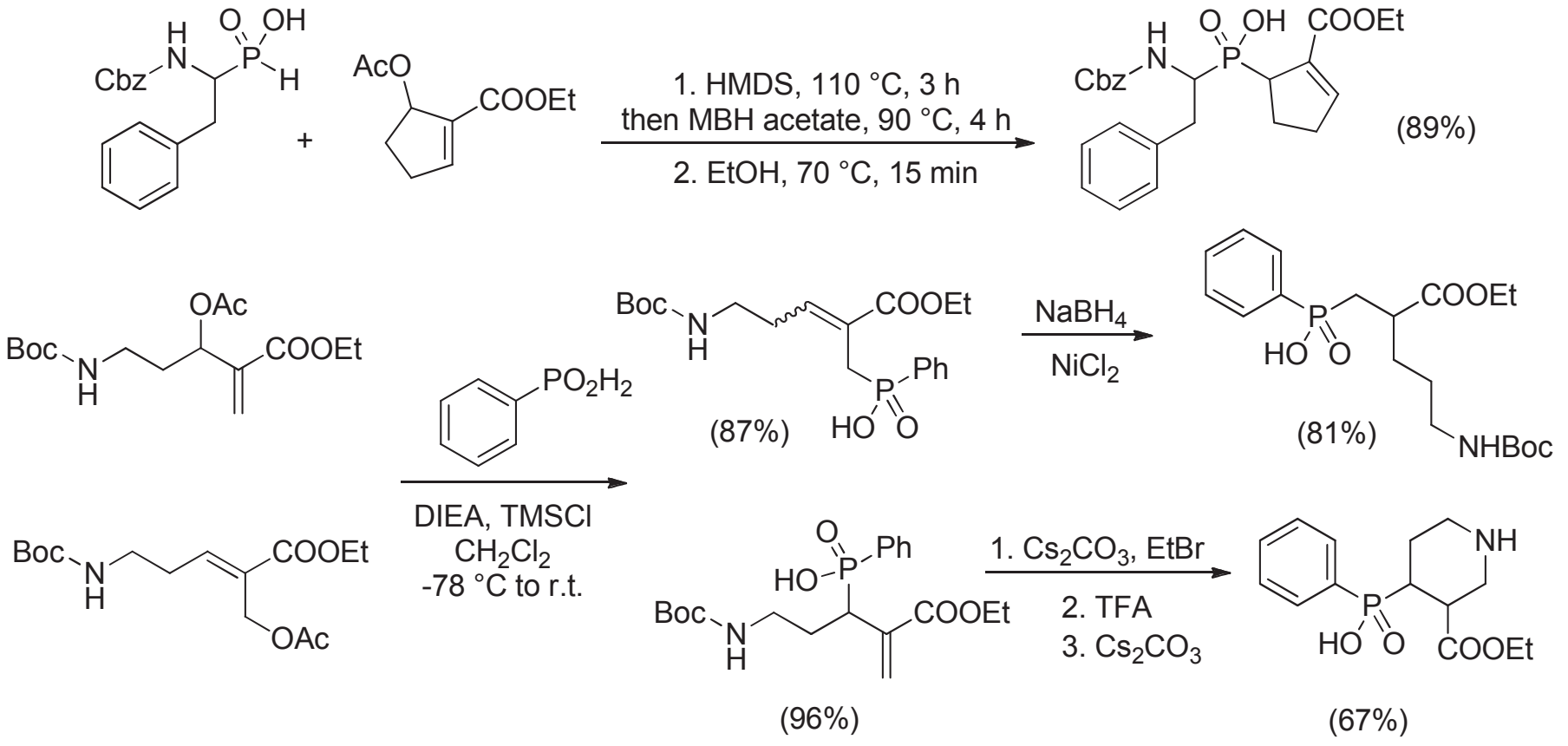

Scheme 6. Application of nucleophilic substitution of silylated $H$-phosphinic acids to $\mathrm{MBH}$ acetates to obtain cyclic and linear phosphinate building blocks of pseudopeptidic inhibitors of metalloproteases. 
Carbonates as allyl system activators and phosphine oxides $\left(\mathrm{HP}(\mathrm{O}) \mathrm{R}_{2}\right)$ as attacking nucleophile were also tested. Sun and co-workers, in their search for an asymmetric version of the substitution, stated that diethylphosphine oxide reacts with $\mathrm{MBH}$ carbonates to give the typical $\mathrm{S}_{\mathrm{N}} 2$ ' substitution product under strong base catalysis $(\mathrm{NaOH})($ Scheme 7$) .{ }^{17}$ However, when the reaction is catalyzed with a weaker base (e.g., a firstgroup metal carbonate) and a chiral auxiliary ( 20 mol\% quinidine) is added, the regioselectivity is inverted, and an asymmetric induction is observed. Under chiral organocatalytic mediation, aromatic $\mathrm{MBH}$ carbonates gave rise to secondary phosphorus adducts with good yields and an excellent ee, exceeding $90 \%$ with a single exception of a heteroaromatic (2-furyl) case. Apparently, the mechanism involves an $\mathrm{S}_{\mathrm{N}} 2$ '- $\mathrm{S}_{\mathrm{N}} 2$ ' substitution sequence with a quinidinium salt intermediate. Alkylphosphine oxides other than diethyl react comparably.

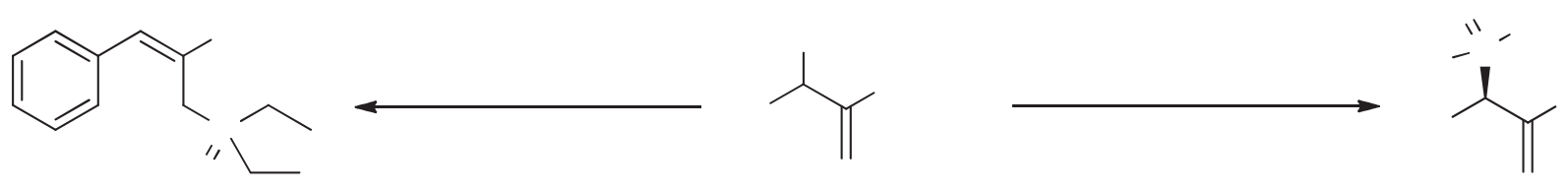

Scheme 7. Reaction of a phosphine oxide with an MBH carbonate involving enantioselective induction with quinidine.

The stereoselective methodology was virtually reproduced in a parallel paper by the same authors. ${ }^{18}$ Diaryl phosphine oxides were substituted to aryl-derived $\mathrm{MBH}$ carbonates and yielded the enantioenriched products of the general structure depicted in Scheme 7 (yield 55-98\%, ee 76-97\%, again with the exception of 2-furyl, $44 \%)$. The reaction conditions were only marginally modified, and molecular sieves were used as an additive alternative to sodium carbonate.

Related studies were continued by Deng and Shi, who prepared thiourea catalysts and tested them for the asymmetric displacement of $\mathrm{MBH}$ carbonates with diphenyl phosphine oxides and diphenyl phosphites (Scheme 8). ${ }^{19}$ For both substrates, the catalysis gave products with very good preparative yield and stereoselectivity. The reaction conditions were comparable to those applied for quinidine-assisted reactions. Using the catalyst depicted in Scheme 8, tertiary phosphine oxides of an absolute configuration opposite to that of the quinidine approach were obtained. For the phosphonate products, the configuration was not assigned.
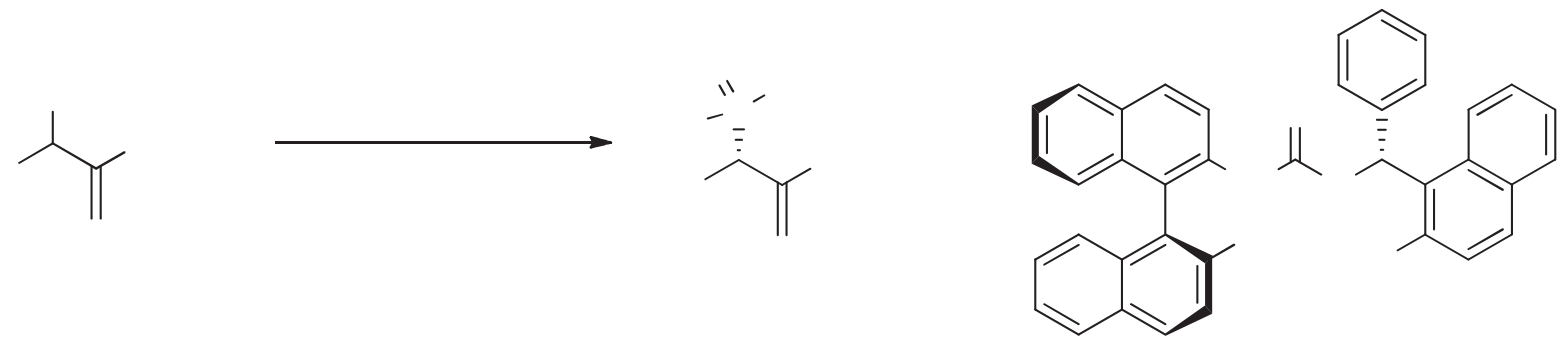

Scheme 8. A thiourea-catalyzed substitution of allyl carbonates with diphenyl phosphine oxides and diphenyl phosphites. 
As mentioned above and elsewhere, ${ }^{20}$ the organocatalytic substitution of the $\mathrm{MBH}$ acetates with $\mathrm{P}$ nucleophiles implicates the two-step $\mathrm{S}_{\mathrm{N}} 2^{\prime}-\mathrm{S}_{\mathrm{N}} 2^{\prime}$ mechanism and the formation of secondary allyl products. As the overall result, the attacking nucleophile occupies the position of the leaving group. This was also confirmed for cyclic acetates, which were regioselectively converted into corresponding $\gamma$-keto allylphosphonates with triethyl phosphite in 70-93\% yield (Scheme 9). ${ }^{21}$ The substitution worked efficiently with structurally diverse linear or branched alkyl and aryl groups and for other nucleophiles.

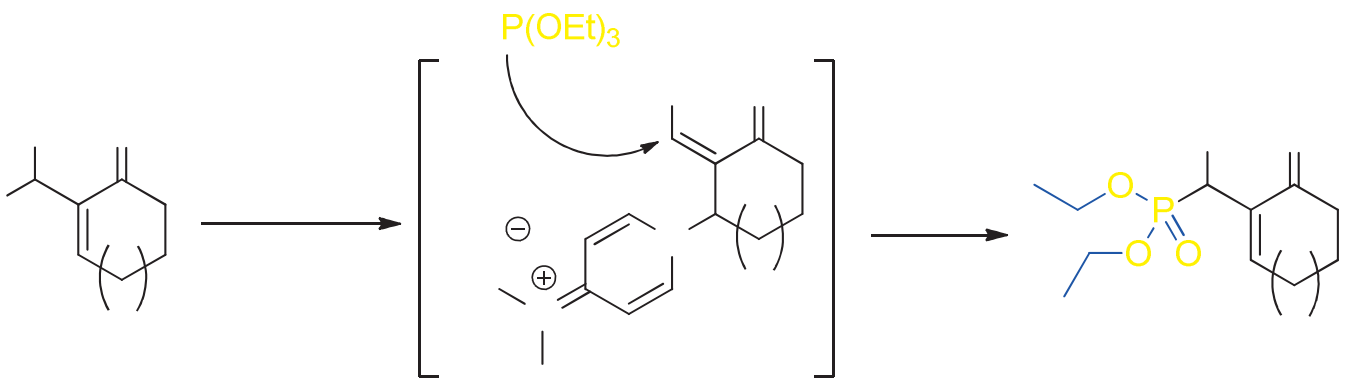

Scheme 9. Organocatalytic $S_{N} 2 '-S_{N} 2$ ' substitution of cyclic allyl ketones with triethyl phosphite.

An oxygen-derived leaving group can be activated not only by a covalent modification. Das and co-workers presented an interesting method to obtain primary phosphonates starting from allyl alcohols, the original $\mathrm{MBH}$ adducts. ${ }^{22}$ Under normal conditions, such systems should be rather reactive in a Michael-type addition and produce $\mathrm{p}$-hydroxyphosphorus species. Quite surprisingly, this subject is practically unexplored in the literature. The group of Swamy reported the addition of cyclic phosphites and thiophosphites to aromatic $\mathrm{MBH}$ alcohols (Scheme 10). ${ }^{23}$ The reaction proceeded in an ionic liquid in the presence of TBAF with a conversion exceeding 90\%. According to the postulated mechanism, the phosphorus is fluorinated to a pentavalent bipyramidal fluorophosphonate intermediate that is subsequently prone to nucleophilic addition to the activated unsaturated system.
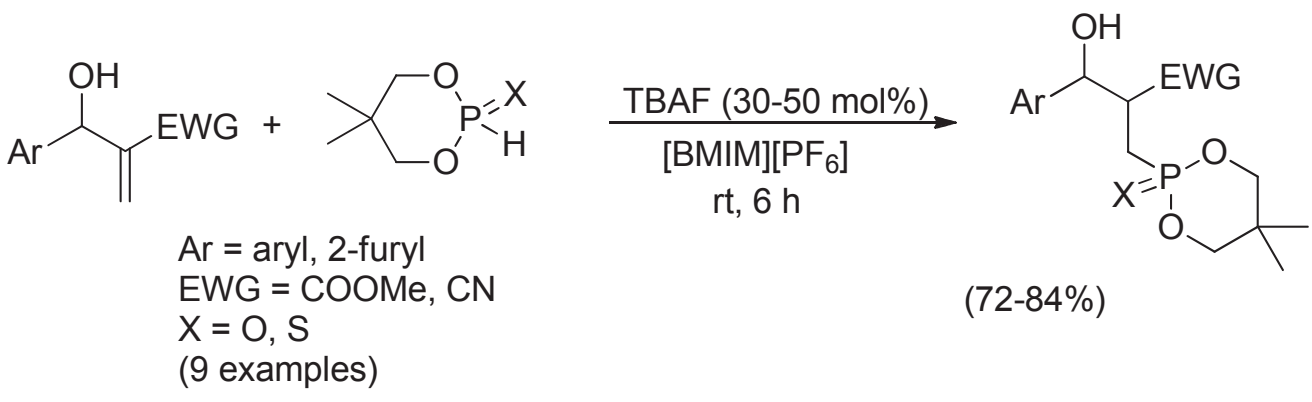

$(72-84 \%)$

(9 examples)

Scheme 10. A phospha-Michael addition of cyclic $>\mathrm{P}(\mathrm{O}) \mathrm{H}$ species to $\mathrm{MBH}$ alcohols.

Turning back to the work of Das et al., ${ }^{22}$ the authors triggered $\mathrm{OH}$ activation to produce a good leaving group in allyl alcohols with the addition of a Lewis acid. Different metal chlorides were tested, and $\mathrm{FeCl}_{3}$ in boiling toluene was found to be optimal (Scheme 11). The yield for a range of aliphatic and aromatic substrates was practically quantitative. Again, the $Z$ isomer of the final compounds was exclusively produced. The authors suggested a two-step mechanism of the substitution leading via intermediate allyl chlorides and $\mathrm{Fe}(\mathrm{OH}) \mathrm{Cl}_{2}$ elimination, followed by an Arbuzov reaction with the $\mathrm{P}(\mathrm{III})$ reactant. 


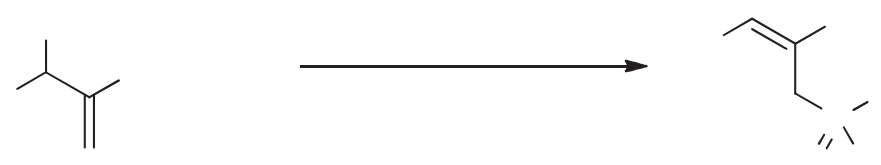

Scheme 11. Allyl substitution of $\mathrm{MBH}$ alcohols with trialkyl phosphites mediated by a Lewis acid.

\section{Reactivity of the Morita-Baylis-Hillman Bromides with Phosphorus Nucleophiles}

The scope, mechanism and regioselectivity of the reaction of the $\mathrm{MBH}$ halides with phosphorus nucleophiles avoids unambiguous generalization, similar to the oxygen-based leaving groups. In early work by McFadden et al., who examined allyl chlorides and bromides obtained from $\mathrm{MBH}$ alcohols, in the reaction with trialkyl phosphites, a competition between the $\mathrm{S}_{\mathrm{N}} 2$ and $\mathrm{S}_{\mathrm{N}} 2$ ' Arbuzov displacements became evident (Scheme 12). ${ }^{24}$ The substitution of the halomethacrylate derivatives occurred in the $\alpha$ and $\gamma$ allylic positions, with the ratio depending on the reaction conditions and the structure of the reactants, giving a mixture of primary and secondary phosphonates.
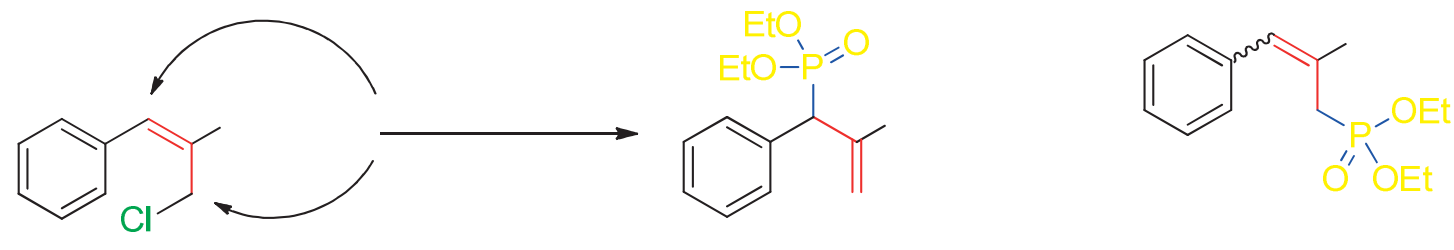

Scheme 12. Competition of $\mathrm{S}_{\mathrm{N}} 2^{\prime}$ and $\mathrm{S}_{\mathrm{N}} 2$ mechanisms of Arbuzov substitution of an $\mathrm{MBH}$ chloride with triethyl phosphite.

Other phosphorus species have a similar tendency to react in two ways, typically with a predominant preference for $\mathrm{S}_{\mathrm{N}} 2^{\prime}$. For example, diphenylphosphine oxide reacted with methyl $\alpha$-bromomethylcinnamate to produce a mixture of two products corresponding to those shown in Scheme 12 . When $\mathrm{K}_{2} \mathrm{CO}_{3}$ was added as a base, the ratio was 70:30, while for $\mathrm{Et}_{3} \mathrm{~N}$, it was 60:40 ( $\mathrm{S}_{\mathrm{N}} 2^{\prime}$ to $\left.\mathrm{S}_{\mathrm{N}} 2\right){ }^{25}$

Total regioselectivity has been rarely reported and concerns particular reactants and/or specific reaction conditions. Such a unique observation was described by Béji et al. ${ }^{26}$ Dimethyl bromomethylfumarate reacted stereoselectively with the diethyl phosphite anion at low temperature to produce exclusively a secondary phosphonate, the $\mathrm{S}_{\mathrm{N}} 2$ ' product. By comparison, the substitution of the same allyl system with triethyl phosphite produced a mixture of primary and secondary phosphonates. Cyclic phosphites and thiophosphites, studied by Balaraman et al. for their reactivity with aryl $\mathrm{MBH}$ bromides, both esters and nitriles, also gave rise to the pure $\mathrm{S}_{\mathrm{N}} 2^{\prime}$ displacement (Scheme 13). ${ }^{23}$ The reaction proceeded in an ionic liquid and in the presence of fluoride ions. For reactive substrates, byproducts with two phosphorus atoms, resulting from the subsequent phospha-Michael addition of the P-nucleophile to the initial mono-substituted product, were found. 

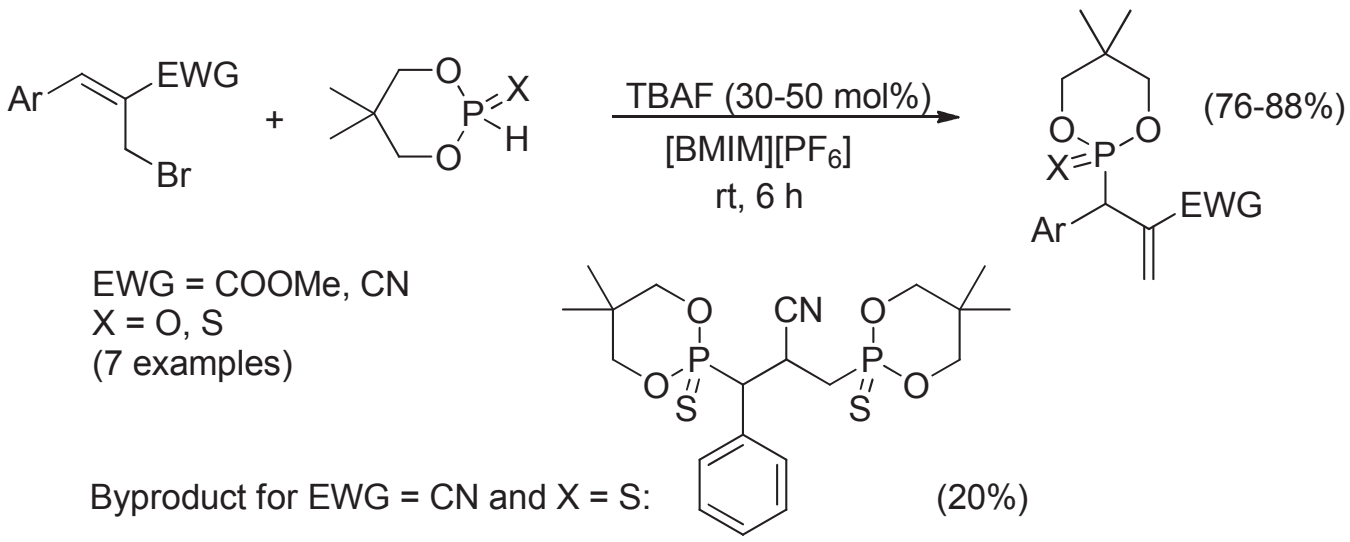

Scheme 13. Regioselective ( $\mathrm{S}_{\mathrm{N}} 2^{\prime}$ exclusively) substitution of the $\mathrm{MBH}$ bromides with cyclic phosphites and thiophosphites, with a byproduct resulting from the subsequent phospha-Michael addition.

The $\mathrm{MBH}$ bromide obtained from formaldehyde is the only case for which the position of the attack is irrelevant. $\alpha$-Bromomethylacrylates are symmetrical with respect to this type of reactivity, and their substitution leads to the same compound, irrespective of the actual mechanism (Scheme 14). ${ }^{27,28}$
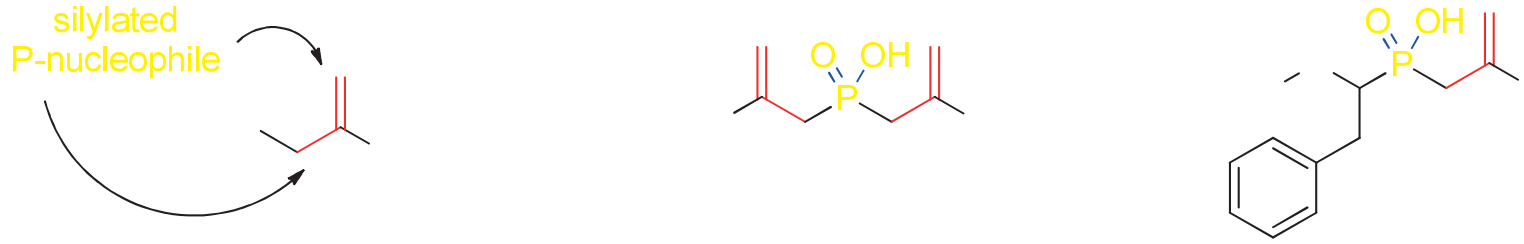

Scheme 14. Representative examples of the allylphosphorus products of the reactions between the silylated $>\mathrm{P}(\mathrm{O}) \mathrm{H}$ species with $\alpha$-bromomethylacrylates.

In a quest to improve the regioselectivity, dedicated nucleophilic auxiliaries have been applied to assist in the organocatalytic halide substitution. In those cases, the catalyst/auxiliary reacts first with the $\mathrm{MBH}$ substrate to produce an alternative leaving group, and then the actual phosphorus nucleophile is added to the pre-formed intermediate salt. Thus, the overall mechanism involves $S_{N} 2-S_{N} 2$ sequential substitutions. Therefore, the overall regio-controlling effect is identical to the $\mathrm{S}_{\mathrm{N}} 2$ '- $\mathrm{S}_{\mathrm{N}} 2$ ' organocatalysis of the displacement in the $\mathrm{MBH}$ acetates and leads to the same secondary organophosphorus products.

Tertiary amines, such as DABCO, have been considered as typical mediators of halide substitution. Yang developed such a protocol for aromatic $\mathrm{MBH}$ bromides and $\mathrm{HP}(\mathrm{O}) \mathrm{X}_{2}$ compounds and obtained the products in

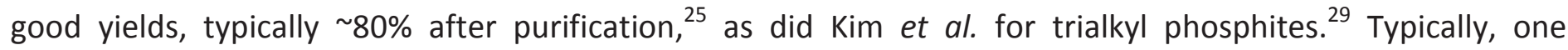
equivalent of DABCO readily formed a quaternary ammonium salt with the substrate, which in turn was substituted regioselectively by a P-nucleophile to give secondary allylphosphine oxides/phosphonates. For a lower excess of DABCO and particular substrates (e.g., nitriles, aliphatic MBH adducts), Kim et al. observed the occurrence of byproducts, in particular secondary vinylphosphonates, the products of a rearrangement. In those instances, using triphenylphosphine instead of DABCO functioned satisfactorily in its organocatalytic function. 
Table 2. Organocatalytic $\mathrm{S}_{\mathrm{N}} 2-\mathrm{S}_{\mathrm{N}} 2^{\prime}$ substitution of Morita-Baylis-Hillman bromides with phosphorus nucleophiles

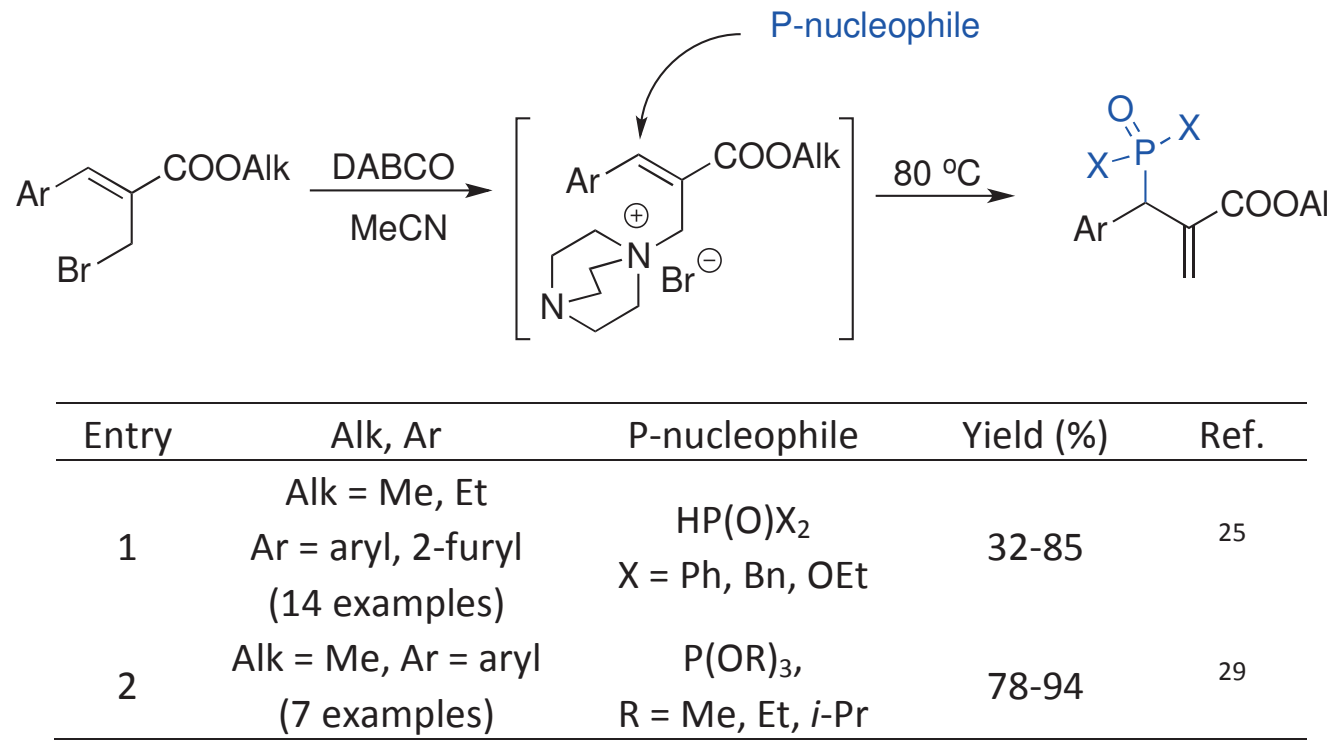

\section{Structural Diversification, Application and Future Potential of Allylphosphonates}

The products of the reaction of phosphorus nucleophiles with $\mathrm{MBH}$ allyl adducts are reactive species and can be further modified or functionalized. Actually, those transformations that produce only intermediate allylphosphonium cations (and further ylides) from phosphines have been studied mostly. ${ }^{30}$ In these cases, the C-P is formed temporarily, typically in situ, and then released upon the final transformation step, e.g., in the Wittig reaction. This chemistry is beyond the scope of this review, as we are merely focused on targeting the final organophosphorus materials containing a permanent C-P bond. Nevertheless, stable phosphorus ylides were also obtained and separated, starting from the $\mathrm{MBH}$ adducts. A Ramirez ylide synthesized by Kim el al. using acetate prepared from $\alpha$-bromocinnamaldehyde and methyl acrylate could be considered as a representative example (Scheme 15). ${ }^{31}$ Attempts at reacting it with benzaldehyde were unsuccessful. This ambient behavior in the Wittig reaction is clearly caused by the aromaticity of the cyclopentadienyl anion. Instead, its synthetic potential is located in organometallic chemistry.
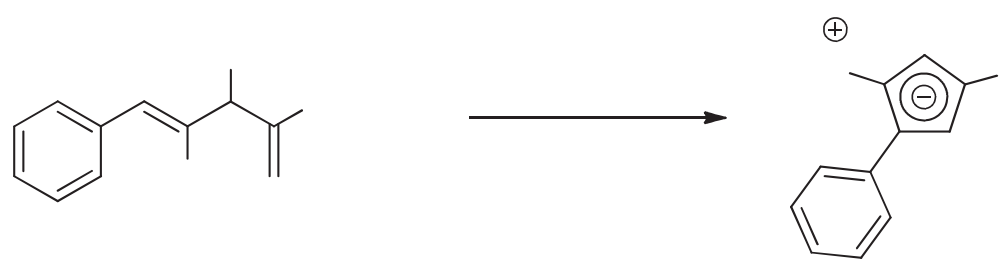

Scheme 15. Synthesis of a stable Ramirez ylide resistant to Wittig reaction.

The allylphosphonate possessing an additional carboxy ester group and the acidic methylene (methine), obtained from an $\alpha$-bromomethylfumarate, an $\mathrm{MBH}$ bromide, could be an example of another type of C-P compound that utilizes the reactivity of the phosphonate group. The phosphonocarboxylate easily underwent the Wittig-Horner reaction with aldehydes to afford unsaturated compounds (here, dienes) with reasonable yield and diastereoselectivity (Scheme 16). ${ }^{26}$ 


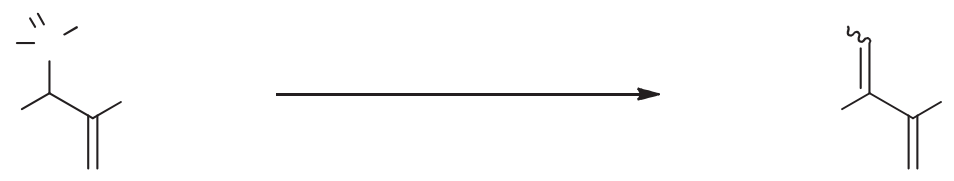

Scheme 16. Wittig-Horner reaction of a phosphonocarboxylate obtained from the MBH bromide.

Modification and derivatization that do not alter the carbon-to-phosphorus linkage mostly concern the conjugated double bond. Reduction, oxidation, bromination, arylation and Michael addition are transformations that are frequently applied as the chief operations of multistep procedures leading to target materials. For example, the enantioselective catalytic hydrogenation of 2-phosphonomethylpropenoates is an obvious way to obtain chiral phosphonopropanoic acids. The last-mentioned compounds are of interest because of their biological activity, mainly in the inhibition of metalloproteases. Spilling and co-workers performed fundamental studies on the stereo-controlled reduction, testing a broad selection of chiral catalysts, ligands and reaction conditions. ${ }^{12}$ After extensive optimization, complex (R)-Cl-MeO-BIPHEP-Ru applied in basic conditions was found to be satisfactorily selective (ee up to 91\%, Table 3, Entry 1). The reduction of unsaturated phosphonates in the form of a free carboxylic acid was more effective. The absolute configuration of the phenyl-substituted product was judged to be $R$.

Table 3. Enantioselective catalytic hydrogenation of 2-phosphonomethylpropenoates

\begin{tabular}{|c|c|c|c|c|c|}
\hline Entry & Alk, $R$ & Chiral complex/ligand & Conditions & $e e(\%)$ & Ref. \\
\hline 1 & $\begin{array}{c}\text { Alk }^{1}=H, \text { Alk }^{2}=\text { Me } \\
R=\text { Me, aryl, 2-furyl } \\
\text { (7 examples) }\end{array}$ & & $\begin{array}{c}\mathrm{H}_{2}, 125 \mathrm{psi}, \mathrm{Et}_{3} \mathrm{~N} \\
\mathrm{MeOH}\end{array}$ & $58-91$ & 12 \\
\hline 2 & $\begin{array}{c}\text { Alk }^{1}=\mathrm{Et}, \mathrm{Alk}^{2}=\mathrm{Me} \\
\mathrm{R}=\text { aryl, } 2 \text {-furyl, } 2- \\
\text { thienyl (9 examples) }\end{array}$ & & $\begin{array}{c}\mathrm{H}_{2}, 10 \text { bar, } \\
{\left[\mathrm{Rh}(\mathrm{COD})_{2}\right] \mathrm{SbF}_{6},} \\
\mathrm{CH}_{2} \mathrm{Cl}_{2}, \mathrm{rt}, 24 \mathrm{~h}\end{array}$ & $91-98$ & 32 \\
\hline 3 & vide supra & & vide supra & $90-98$ & 33 \\
\hline
\end{tabular}

Wang et al. synthesized novel chiral ferrocenyl diphosphine ligands that worked perfectly in the rhodiumcatalyzed asymmetric hydrogenation of allylphosphonate esters. The application of $\left(R_{c}, S_{F e}\right)$ ImiFerroPhos ensured a conversion exceeding 95\%, with an isolated yield of 91-99\% and enantiomeric excess of $91-98 \%$ for 
aromatic and heteroaromatic derivatives (Table 3, Entry 2). ${ }^{32}$ An alkyl (isopropyl) analogue gave rise to a low conversion. The same excellent results were reproduced for the structurally modified amine ligand $\left(R_{c}, S_{F e}\right)$ TaniaPhos (Table 3, Entry 3). ${ }^{33}$

Starting from a simple and commercially available allylphosphonate, Fields ${ }^{34}$ accomplished a reductionoxidation protocol to obtain phosphonothrixin, a natural herbicide ${ }^{35,36}$ (Scheme 17). First, the carboxy ester was reduced to the alcohol, the hydroxyl group of which was subsequently protected as a silyl ether. Then, the double bond was oxidized with osmium oxide to afford a vicinal diol. The secondary OH group of the diol was further oxidized to ketone. Deprotection completed the reaction sequence to give the final dihydroxyketophosphonic with a $24 \%$ overall yield for the six steps. The approach was better than the protocol employing the phosphonylation of methyl bromomethylacrylate as the starting point (overall yield $<8 \%$ ). In this former study, the conversion of the ester to a ketone group via methyl lithium addition appeared critical. $^{37}$

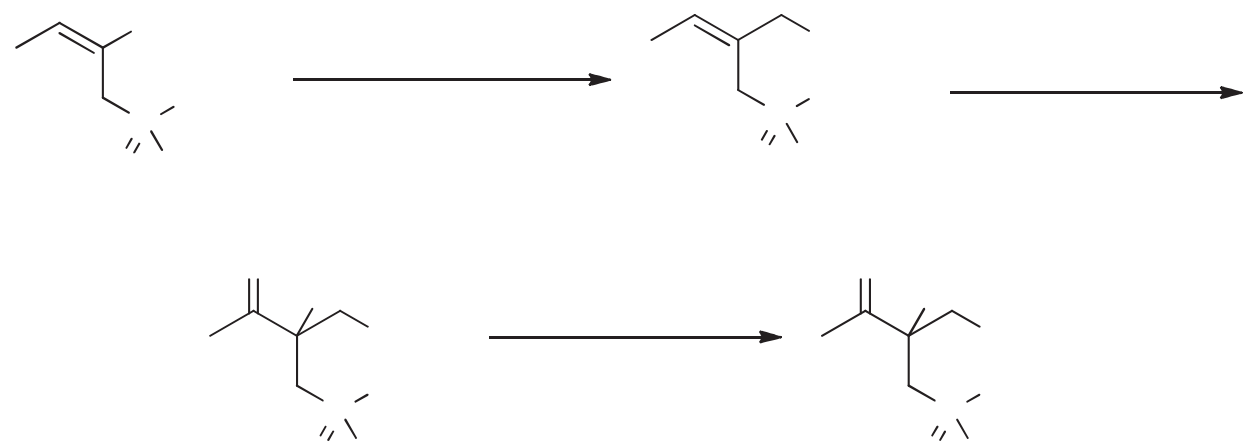

Scheme 17. Synthesis of phosphonothrixin, a natural herbicide, involving the sequential oxidation of an allylphosphonate.

Kraïem et al. applied the bromination of triethyl $\alpha$-phosphonomethylacrylate to obtain the aminosubstituted products. ${ }^{38}$ The addition of bromine to the unsaturated bond of the substrate and subsequent elimination yielded the $\mathrm{MBH}$ bromide, which was used for parallel substitution with alkyl and aryl amines (Scheme 18). Somewhat surprisingly, the final displacement proceeded as an exclusively $\mathrm{S}_{\mathrm{N}} 2^{\prime}$ process and afforded multifunctional compounds, albeit in a moderate to good yield.

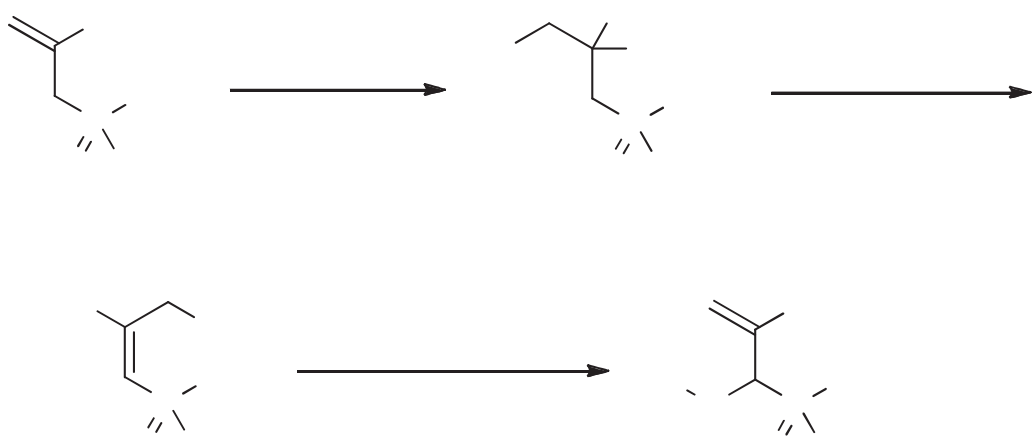

Scheme 18. Synthesis of 2-amino(phosphonomethyl)acrylic esters from allylphosphonates. 
Primary allylphosphonates were subjected to radical bromination by the same authors for further sidechain functionalization. ${ }^{11}$ The allylic position of ethyl 2-(diethoxyphosphorylmethyl)alk-2-enoates was stereoselectively substituted by means of $N$-bromosuccinimide in standard conditions (Scheme 19). The products were supposed to be converted to the corresponding primary allylic alcohols in a two-step formylation-hydrolysis reaction. Indeed, the formylation of butenoate with triethylammonium formate (TEAF, Scheme, $\mathrm{R}=\mathrm{H}$ ) proceeded smoothly and gave ethyl $\beta$-(hydroxymethyl)acrylate (65\% yield after hydrolysis). The formylation of secondary allylic bromides (hexenoates) in the same reaction conditions led exclusively to the buta-1,3-diene derivatives by a $\beta$-elimination of $\mathrm{HBr}$.

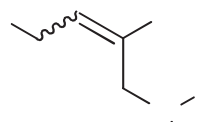

I,

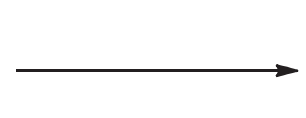

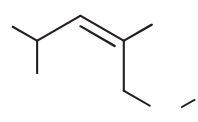

,1
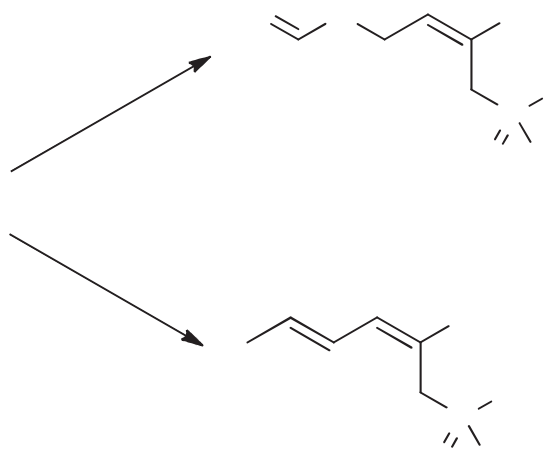

Scheme 19. Formylation of allylphosphonates, following radical bromination, with the course of the reaction depending on the substrate structure.

A palladium-catalyzed oxidative arylation, performed by Lee et al., was proven to be a convenient method to expand the alkenylphosphonate structure. ${ }^{39}$ The cinnamylphosphonate obtained from phenyl-substituted $\mathrm{MBH}$ acetate was reacted with benzene and its derivatives to yield the products, although consisting of two isomers (Scheme 20). The major isomer did not contain the expected allylic system, but rather, was a rearranged vinylphosphonate of exclusive $Z$ geometry. Thus, this main product was not formed in agreement with the typical palladium-catalyzed chelation-assisted mechanism. It was suggested that the regioselectivity of the $\beta$-elimination was not governed by $\mathrm{Pd}$ chelation to the phosphonate group, but rather by steric factors. The vinylphosphonate could be easily converted into its thermodynamically more stable counterpart by means of DBU, but in a non-stereoselective manner, as was shown for the compound substituted with structurally different aryls.
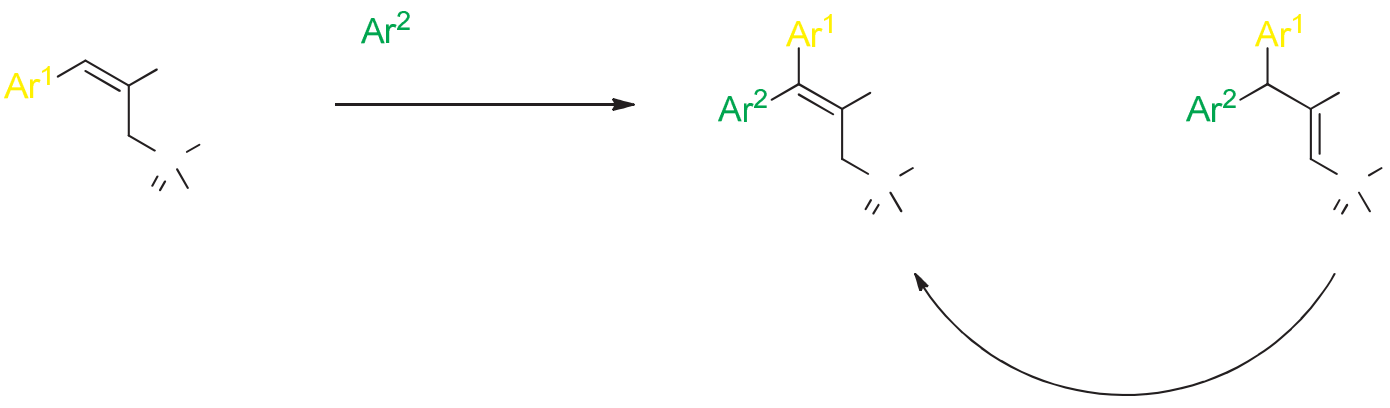

Scheme 20. Palladium-catalyzed oxidative arylation of trialkyl $\alpha$-phosphonomethylcinnamates. 
The arylation of allylphosphonates could also be achieved in a Heck reaction of aryl bromides (iodides) with triethyl $\alpha$-phosphonomethylacrylate. ${ }^{40}$ Various halides, also multifunctional, were coupled stereoselectively in a palladium-mediated process to give products of an elaborated structure (Scheme 21 ). $Z$ isomers were solely obtained in good yields. Apparently, such compounds could be obtained by the most typical substitution of aryl-derived $\mathrm{MBH}$ acetates. However, in continuation of these basic studies, hydroxy or amino-functionalized aryl iodides were applied as the substrates. In these cases, lactone or lactam ring closure involving the ester group led to an aromatic/heterocyclic-fused systems of coumarin, benzoxepinone and quinolinone.
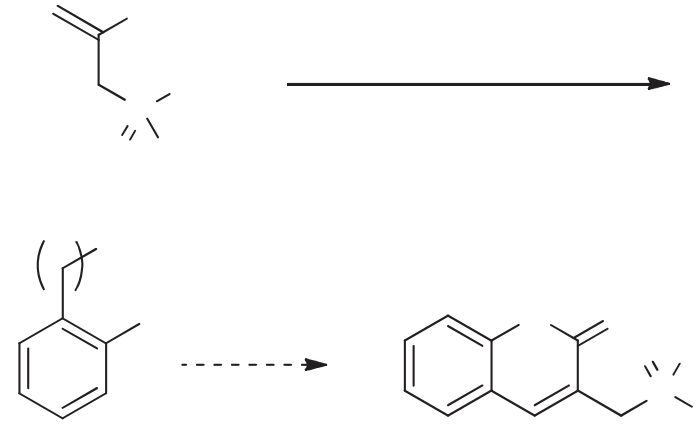
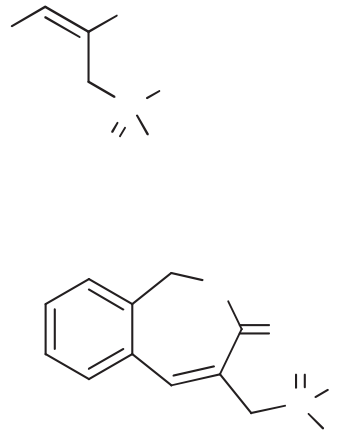

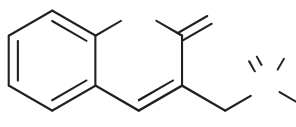

Scheme 21. Heck reaction of aryl halides with triethyl $\alpha$-phosphonometylacrylate. The use of hydroxy, hydroxymethyl and amino ortho-substituted iodobenzenes gave rise to lactone or lactam systems.

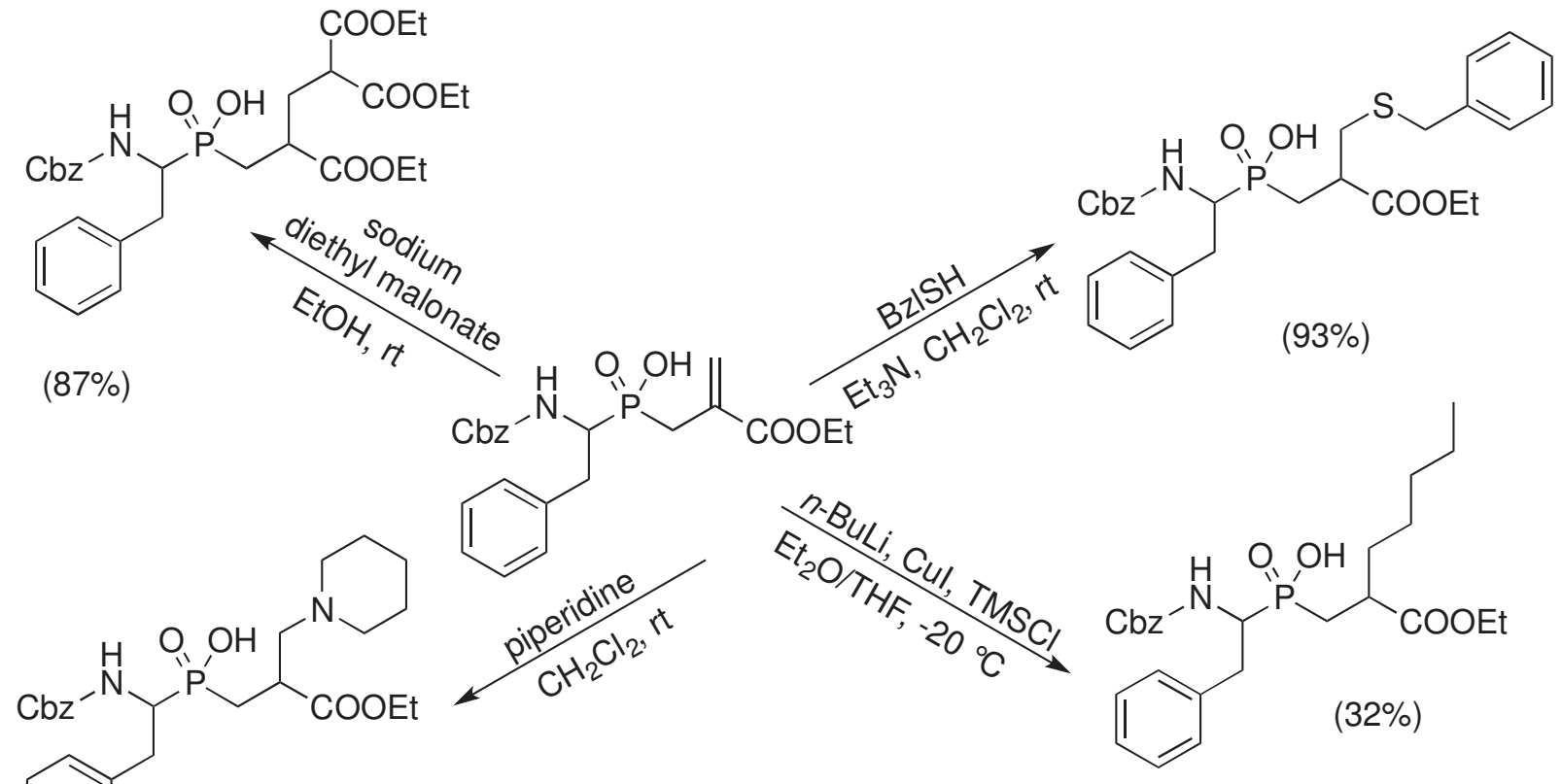

Scheme 22. Diversification potential of the Michael addition of various nucleophiles to P1' dehydroalanine phosphinic dipeptide.

Allylphosphonates/phosphinates originating from $\mathrm{MBH}$ adducts possess an activated double bond system that could be susceptible to Michael addition. Indeed, various nucleophiles were added to the unsaturated 
fragment according to this scenario (see also Schemes 10 and 13). ${ }^{23,28,41}$ The most remarkable achievement was pioneered by the group of Yiotakis, who proved the predisposition of phosphinic dipeptides, the P1' dehydroalanine derivatives, to Michael reaction with carbon, nitrogen and sulfur nucleophiles (Scheme 22). ${ }^{28}$ This allowed the divergent functionalization of the fundamental building block and the preparation of potent metalloprotease inhibitors of a complex structure. In particular, the diversification potential of the dehydroalanine fragment was used to develop novel phosphinic inhibitors of matrix metalloproteases (Scheme 23). ${ }^{28,42}$ The pseudoproline compound allowed the establishment of structural determinants of highly potent and selective ligands of the C-terminal domain of angiotensin-converting enzyme (Scheme 24). ${ }^{16}$
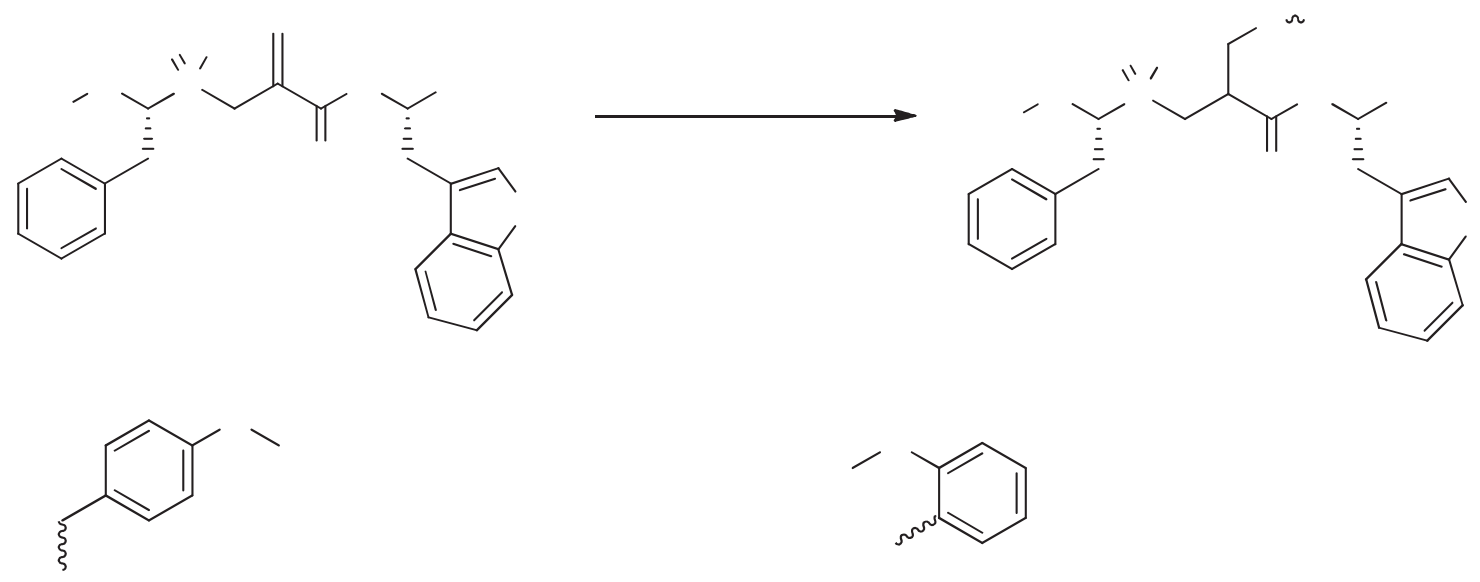

Scheme 23. Potent and selective phosphinic pseudotripeptide inhibitors of matrix metalloproteases (MMPs), obtained by the Michael addition of thiols to the P1' dehydroalanine residue.<smiles>O=C(O)OC(=O)N[C@H](Cc1ccccc1)P(=O)(O)O</smiles>

1. H-Trp(Boc)-Wang HBTU, DIEA, NMP

2. TFA, TIS, DCM then, HPLC separation

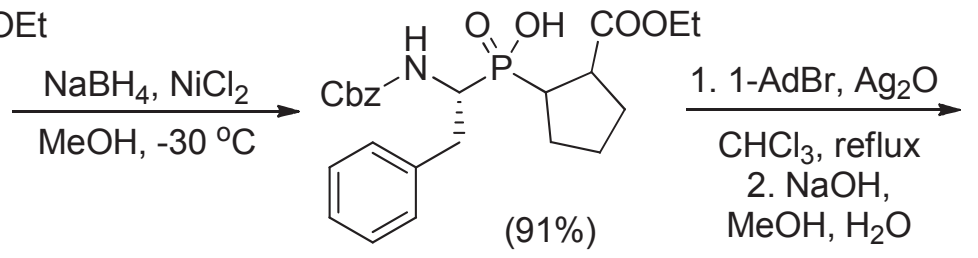

$(91 \%)$<smiles>O=C(O)[C@H](Cc1ccccc1)NC(=O)[C@@H](Cc1c[nH]c2ccccc12)NC(=O)[C@H](Cc1ccccc1)NC(=O)[C@H]1CCC[C@@H]1C(=O)O</smiles>

$K_{\mathrm{i}}=3 \mathrm{nM}$ for ACE, C-domain mutant $K_{\mathrm{i}}=10000 \mathrm{nM}$ for ACE, $\mathrm{N}$-domain mutant

Scheme 24. Synthesis (for the substrate preparation see Scheme 6) and inhibitory activity of a phosphinic tripeptide analogue, a highly selective inhibitor of the C-terminal domain of angiotensin-converting enzyme.

The biological activity aspects of the structurally less complex products of the P-nucleophile reaction with $\mathrm{MBH}$ adducts were also explored. The compounds presented in Scheme 25 were tested as mechanism-based inhibitors of 3-deoxy-D-arabino-heptulosonate 7-phosphate (DAH7P) synthase (an enzyme that catalyzes the first step of the shikimate pathway for aromatic compound biosynthesis) ${ }^{43,44}$ and UDP-N-acetylglucosamine 1carboxyvinyltransferase (MurA, catalyzes the first step of the peptidoglycan biosynthesis). ${ }^{24}$ 


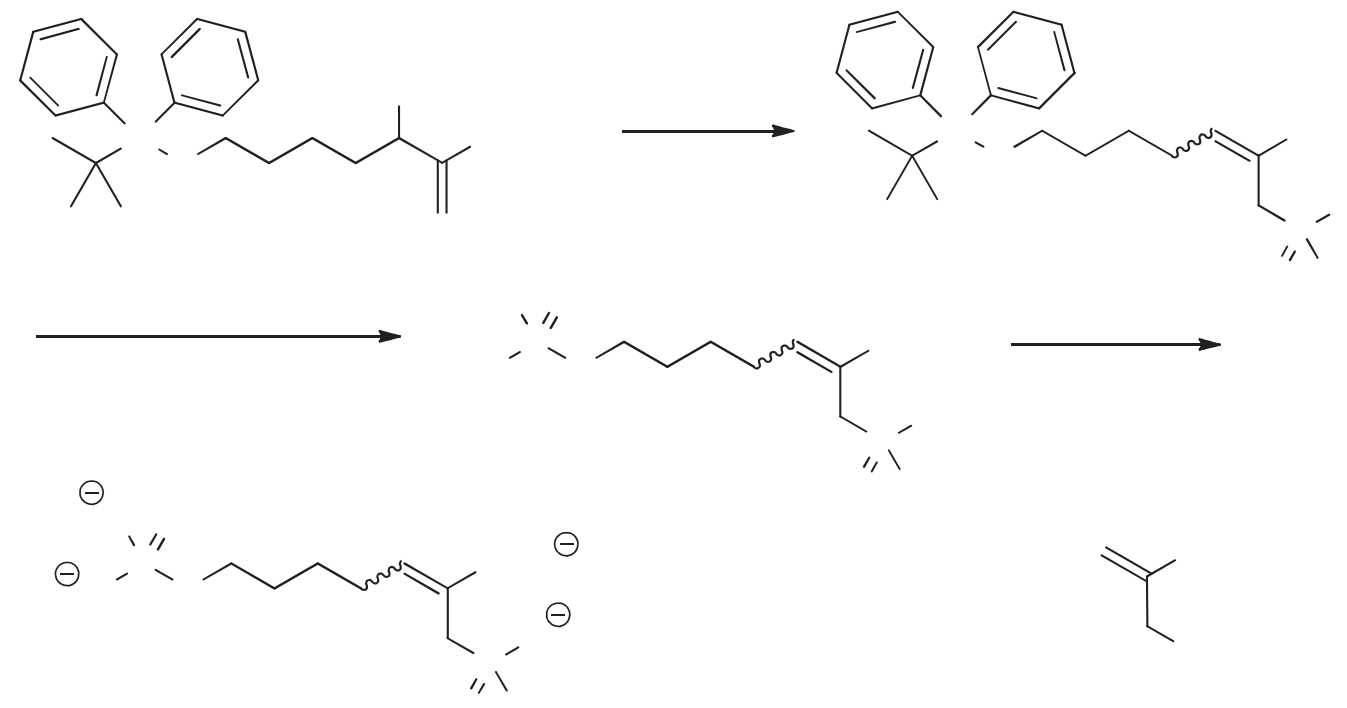

Scheme 25. Biologically active phosphonic acids obtained in synthetic pathways that involve the nucleophilic addition of a trialkyl phosphite to $\mathrm{MBH}$ adducts.

\section{Conclusions}

The general reactivity of a phosphorus nucleophile with Morita-Baylis-Hillman adducts can be summarized as presented in Scheme 26. Tervalent $\mathrm{PX}_{3}$ derivatives and tetravalent $\mathrm{X}(\mathrm{Y}) \mathrm{P}(\mathrm{O}) \mathrm{H}$ react according to these rules, alone or under appropriate activation/catalysis. Certain transformations are non-selective, while in other cases, the reaction conditions promote an exact regio- and stereoselectivity of substitution. The latter are of invaluable importance. Knowing the mechanisms of the control, an allylphosphorus of a particular structure can be conveniently obtained.

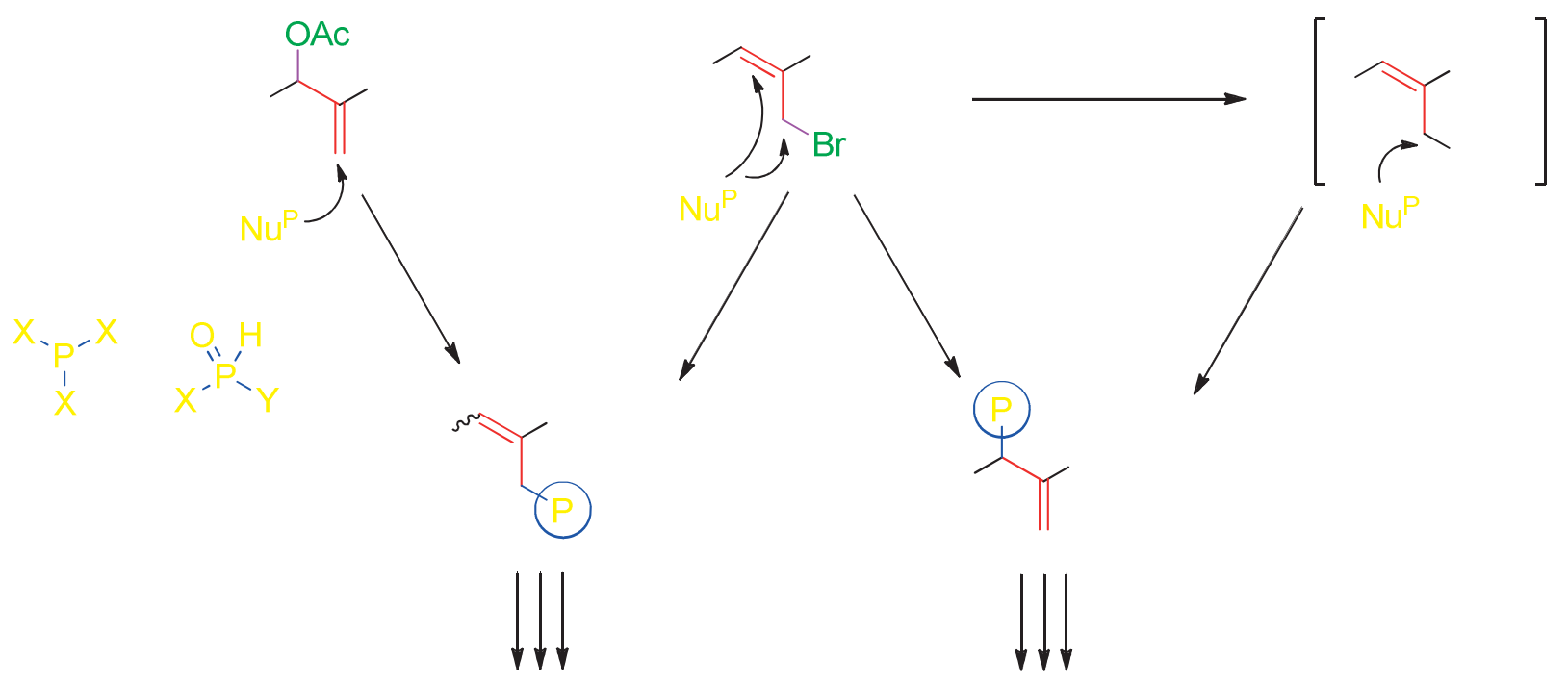

Scheme 26. Outline of synthetic feasibility of the reaction of MBH adducts with phosphorus nucleophiles. 
The products of these substitutions, trifunctional electron-withdrawing group-functionalized allylphosphonates (phosphinates, phosphine oxides, etc.), are compounds of growing interest. They can also be conveniently modified, as they are susceptible to diverse synthetic transformations, such as Michael-type nucleophilic additions, cross-couplings, cyclocondensations, and many others. As a result, the chemistry becomes the source of complex structures, including biologically active compounds and chiral ligands or catalysts. These applications seem to possess an immense future potential, and the accessibility of advanced organophosphorus products is expected to be addressed in these methodologies.

\section{Acknowledgements}

This work was supported by a grant from the Polish National Science Centre (Grant 2013/09/B/ST5/00090).

\section{References}

1. Morita, K.; Suzuki Z.; Hirose, H. Bull. Chem. Soc. Jpn. 1968, 41, 2815.

http://dx.doi.org/10.1246/bcsj.41.2815

2. Baylis, A. B.; Hillman, M. E. D. German Patent 2155113, 1972.

3. Shi, M.; Wang, F.-J.; Zhao, M.-X.; Wei. Y. The chemistry of the Morita-Baylis-Hillman reaction. RSC Publishing, Cambridge, 2011.

4. Basavaiah, D.; Veeraraghavaiah, G. Chem. Soc. Rev. 2012, 41, 68. http://dx.doi.org/10.1039/C1CS15174F

5. Basavaiah, D.; Reddy, B. S.; Badsara, S. S. Chem. Rev. 2010, 110, 5447. http://dx.doi.org/10.1021/cr900291g

6. Declerck, V.; Martinez, J.; Lamaty, F. Chem. Rev. 2009, 109, 1. http://dx.doi.org/10.1021/cr068057c

7. Wei, Y.; Shi, M. Chem. Rev. 2013, 113, 6659. http://dx.doi.org/10.1021/cr300192h

8. Singh, V.; Batra, S. Tetrahedron 2008, 64, 4511.

http://dx.doi.org/10.1016/i.tet.2008.02.087

9. Trost, B. M. J. Org. Chem. 2004, 69, 5813. http://dx.doi.org/10.1021/jo0491004

10. Basavaiah, D.; Pandiaraju. S. Tetrahedron, 1996, 52, 2261.

http://dx.doi.org/10.1016/0040-4020(95)01055-6

11. Kraïem, H.; Amri, H. Phosphorus, Sulfur, Silicon 2007, 182, 2555.

http://dx.doi.org/10.1080/10426500701509329

12. Badkar, P. A.; Rath, N. P., Spilling, C. D. Org. Lett. 2007, 9, 3619.

http://dx.doi.org/10.1021/ol701500s

13. Janecki, T.; Bodalski, R. Synthesis 1990, 799.

http://dx.doi.org/10.1055/s-1990-27019

14. Krawczyk, E.; Owsianik, K.; Skowrońska, A. Tetrahedron 2005, 61, 1449. http://dx.doi.org/10.1016/j.tet.2004.12.008

15. Kalyva, M.; Zografos, A. L.; Kapourani, E.; Giambazolias, E.; Devel, L.; Papakyriakou, A.; Dive, V.; Lazarou, Y. G.; Georgiadis, D. Chem. Eur. J. 2015, 21, 3278. 
http://dx.doi.org/10.1002/chem.201405626

16. Georgiadis, D.; Cuniasse, P.; Cotton, J.; Yiotakis, A.; Dive, V. Biochemistry 2004, 43, 8048. http://dx.doi.org/10.1021/bi049504q

17. Sun, W.; Hong, L.; Liu, C.; Wang, R. Org. Lett. 2010, 12, 3914. http://dx.doi.org/10.1021/ol101601d

18. Hong, L.; Sun, W.; Liu, C.; Zhao, D., Wang, R. Chem. Commun. 2010, 46, 2856. http://dx.doi.org/10.1039/b926037d

19. Deng, H.-P.; Shi, M. Eur. J. Org. Chem. 2012, 183.

http://dx.doi.org/10.1002/ejoc.201101365

20. Du, Y.; Han, X.; Lu, X. Tetrahedron Lett. 2004, 45, 4967. http://dx.doi.org/10.1016/j.tetlet.2004.04.135

21. Elleuch, H.; Ayadi, M.; Bouajila, J.; Rezgui, F. J. Org. Chem. 2016, 81, 1757. http://dx.doi.org/10.1021/acs.joc.5b02106

22. Das, B.; Bhunia, N.; Damodar, K. Synth. Commun. 2012, 42, 2479. http://dx.doi.org/10.1080/00397911.2011.561396

23. Balaraman, E.; Srinivas, V.; Swamy, K. C. K. Tetrahedron 2009, 65, 7603. http://dx.doi.org/10.1016/j.tet.2009.06.096

24. McFadden, H. G.; Harris, R. L. N.; Jenkins, C. L. D. Aust. J. Chem. 1989, 42, 301. http://dx.doi.org/10.1071/CH9890301

25. Yang, L.; Xu, L.; Yu, C. Phosphorus, Sulfur, Silicon 2009, 184, 2049. http://dx.doi.org/10.1080/10426500802418545

26. Béji, F.; Lebreton, J.; Villiéras, J.; Amri, H. Synth. Commun. 2002, 32, 3273. http://dx.doi.org/10.1081/SCC-120014031

27. Majewski, P. Phosphorus, Sulfur Silicon 1989, 45, 151. http://dx.doi.org/10.1080/10426508908045011

28. Matziari, M.; Georgiadis, D.; Dive, V.; Yiotakis, A. Org. Lett. 2001, 3, 659. http://dx.doi.org/10.1021/ol0069103

29. Kim, S. H.; Kim, S. H.; Lee, H. S.; Nyoung, J. Kim Bull. Korean Chem. Soc. 2013, 34, 133. http://dx.doi.org/10.5012/bkcs.2013.34.1.133

30. Liu, T.-Y.; Xie M.; Chen, Y.-C. Chem. Soc. Rev. 2012, 41, 4101. http://dx.doi.org/10.1039/c2cs35017c

31. Kim, K. H.; Lee, S.; Lee, J.; Kim, J. N. Tetrahedron Lett. 2015, 56, 4349. http://dx.doi.org/10.1016/j.tetlet.2015.05.083

32. Wang, D.-Y.; Hu, X.-P.; Hou, C.-J.; Deng, J.; Yu, S.-B.; Duan, Z.-C.; Huang, J.-D.; Zheng, Z. Org. Lett. 2009, 11, 3226. http://dx.doi.org/10.1021/ol9012469

33. Luo, L.-B.; Wang, D.-Y.; Zhou, X.-M.; Zheng, Z.; Hu, X.-P. Tetrahedron: Asymmetry 2011, 22, 2117. http://dx.doi.org/10.1016/j.tetasy.2011.12.002

34. Fields, S. C. Tetrahedron Lett. 1998, 39, 6621. http://dx.doi.org/10.1016/S0040-4039(98)01403-8

35. Takahashi, E.; Kimura, T.; Nakamura, K.; Arahira, M.; lida, M. J. Antibiot. (Tokyo) 1995, 48, 1124. http://dx.doi.org/10.7164/antibiotics.48.1124

36. Kimura, T.; Nakamura, K.; Takahashi, E. J. Antibiot. (Tokyo) 1995, 48, 1130. 
http://dx.doi.org/10.7164/antibiotics.48.1130

37. Nakamura, K.; Kimura, T.; Kanno, H.; Takahashi, E. J. Antibiot. (Tokyo) 1995, 48, 1134.

http://dx.doi.org/10.7164/antibiotics.48.1134

38. Kraïem, H.; Abdullah, M. I.; Amri, H. Tetrahedron Lett. 2003, 44, 553.

http://dx.doi.org/10.1016/S0040-4039(02)02589-3

39. Lee, H. S.; Lim, C. H.; Lee, H. J.; Kim, J. N. Bull. Korean Chem. Soc. 2012, 33, 3817.

http://dx.doi.org/10.5012/bkcs.2012.33.11.3817

40. Abdelli, A.; Gaucher, A.; Efrit, M. L.; M'rabet, H.; Prim, D. Tetrahedron Lett. 2015, 56, 1679. http://dx.doi.org/10.1016/j.tetlet.2015.02.038

41. Abdelli, A.; M'rabet, H.; Efrit, M. L.; Gaucher, A.; Prim, D. J. Sulfur Chem. 2014, 35, 674. http://dx.doi.org/10.1080/17415993.2014.951856

42. Matziari, M.; Beau, F.; Cuniasse, P.; Dive, V.; Yiotakis, A. J. Med. Chem. 2004, 47, 325. http://dx.doi.org/10.1021/jm0308491

43. Walker, S. R.; Cumming, H.; Parker, E. J. Org. Biomol. Chem. 2009, 7, 3031. http://dx.doi.org/10.1039/b909241b

44. Walker, S. R.; Jiao, W.; Parker, E. J. Bioorg. Med. Chem. Lett. 2011, 21, 5092. http://dx.doi.org/10.1016/j.bmcl.2011.03.071

\section{Authors' Biographies}

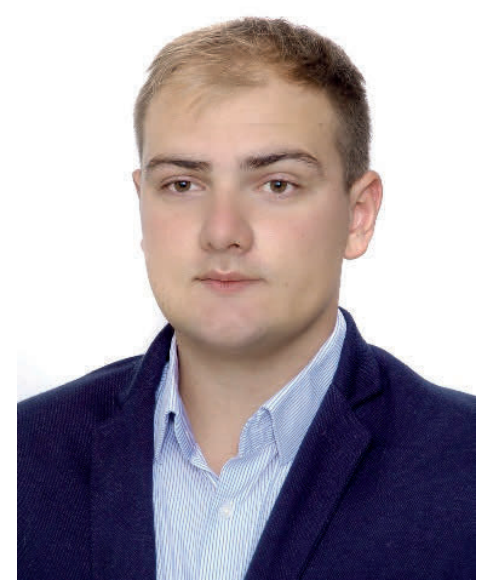

Michał Talma was born in 1991. He studied biotechnology at the Faculty of Chemistry, Wrocław University of Technology, Poland. He gained the M.Sc. degree in 2015 on immobilization of drugs in porous structures under supervision of Dr. Łukasz Radosiński. Currently, he is a PH.D. student at the Department of Bioorganic Chemistry with Prof. Artur Mucha. The topic of his thesis involves synthesis of bioactive phosphinic compounds starting from the Morita-Baylis-Hillman adducts. 


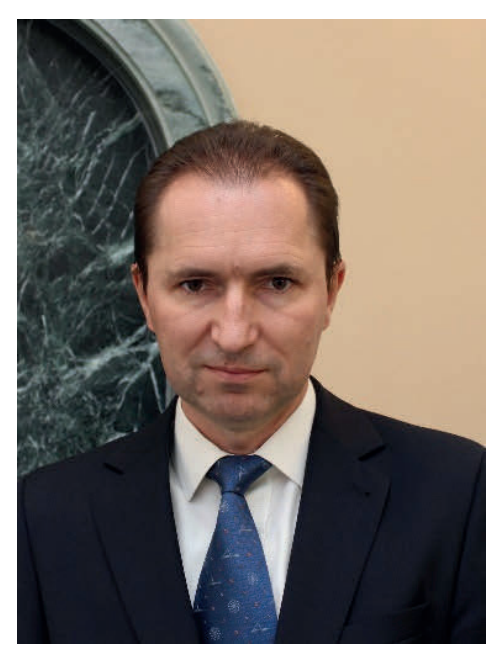

Artur Mucha studied chemistry at Wrocław University of Technology, Poland and was graduated in 1988. In 1994 he gained a Ph.D. on synthesis and transformations of aminophosphinic acids with Prof. Roman Tyka. He took a 2-year postdoctoral fellowship in the Département d'Ingénierie et d'Etudes des Protéines, CEA Saclay, France, with Dr. Vincent Dive. He obtained the D.Sc. degree in 2007 and was nominated as professor in 2016. Along his professional carrier Artur Mucha has been employed at the Faculty of Chemistry, Wrocław University of Technology and currently he is a professor at the Department of Bioorganic Chemistry. His scientific interests are focused on synthesis of organophosphorus compounds, mainly amino acid analogs and peptidomimetics, and their application in drug discovery and medicinal chemistry. The biological aspect his activity mainly relates to inhibition of metalloproteases. 